\title{
Increased Osteogenic Differentiation of Periodontal Ligament Stem Cells on Polydopamine Film Occurs via Activation of Integrin and PI3K Signaling Pathways
}

\author{
Jeong Seok Lee ${ }^{a}$ Jin-Kyu Yib Seong Yeong An ${ }^{a}$ Jung Sun Heo \\ aDepartment of Maxillofacial Biomedical Engineering and Institute of Oral Biology, School of Dentistry, \\ Kyung Hee University, ${ }^{b}$ Department of Conservative Dentistry, School of Dentistry, Kyung Hee \\ University, 26 Kyunghee-daero, Dongdaemun-gu, Seoul, South Korea
}

\section{Key Words}

Polydopamine • Periodontal ligament stem cells • Osteogenic differentiation • Integrin • PI3K

\begin{abstract}
Background/Aims: Mussel-inspired polydopamine (PDA) is known to be an effective bioadhesive and bioactive material for controlling stem cell fate, which is important in stem cellbased regenerative medicine; however, the effect of PDA on osteogenic differentiation of periodontal ligament stem cells (PDLSCs) is not fully understood. In this study, we investigated the osteoinductive effect of PDA on PDLSCs and examined how this phenomenon is encouraged. Methods: Osteogenic induction of PDLSCs was established by culturing cells on PDA film or on an uncoated polystyrene surface as a control. Osteogenic differentiation of PDLSCs was assessed by measurement of intracellular calcium levels and alkaline phosphatase (ALP) activity as well as by evaluation of protein expression of osteocalcin (OCN), osterix (OSX), and runt-related transcription factor 2 (RUNX2). Results: The PDLSCs cultured on PDA film showed higher osteogenic activity than those on the control surface. Moreover, PDLSCs on PDA film expressed increased levels of the integrin adhesion receptors integrin $\alpha 5$ and $\beta 1$ compared to control cells. Expression of one isoform of the intracellular signaling protein phosphatidylinositol-3-kinase (PI3K), p110y, was increased in PDLSCs on PDA film in a PDA dose-dependent manner. This signaling protein was found to interact with integrin $\beta 1$, demonstrating integrinlinked PI3K activation in response to PDA. Finally, the blockage of PI3K reduced the PDAinduced osteogenic activity of PDLSCs. Conclusion: our findings suggest that the bioadhesive PDA stimulates osteogenic differentiation of PDLSCs via activation of the integrin $\alpha 5 / \beta 1$ and PI3K signaling pathways.
\end{abstract}

J. S. Lee and J.-K. Yi contributed equally to this study.

Jung Sun Heo, D.V.M., Ph.D.

Department of Maxillofacial Biomedical Engineering and Institute of Oral Biology, School of Dentistry, Kyung Hee University, 26 Kyunghee-daero, Dongdaemun-gu, Seoul 130-701 (South Korea)

Tel. +82-2-961-0470, E-Mail heojs@khu.ac.kr 


\section{Introduction}

Multipotent postnatal stem cells have been previously identified in oral tissue in periodontal ligaments (periodontal ligament stem cells [PDLSCs]) by single colony selection and magnetic activated cell sorting using mesenchymal stem cell surface markers markers [1]. These dental stem cells, which are plentiful and easy to collect from tissue, have been shown to be able to differentiate into many cell types [2-5]. In particular, PDLSCs exhibit osteogenic, chondrogenic, and adipogenic differentiation under controlled culture conditions, as observed for bone marrow-derived mesenchymal stem cells (BMMSCs) [6-8]. Moreover, several studies have shown that dental-derived MSCs have greater differentiation capacities compared with BMMSCs [9-11]. Among the published studies that focused on the osteogenic capability of PDLSCs, one previous study demonstrated a therapeutic potential for autologous PDLSCs by demonstrating significantly increased new bone formation around peri-implantitis defects in an experimental animal model [12]. Indeed, in a comparative experiment to test the bone regeneration capacity of dental-derived MSCs, PDLSCs encouraged more mineralization in the calvarial defects than gingival mesenchymal stem cells (GMSCs), which exhibit less osteogenic differentiation ability in specific stem cell delivery systems [13]. Thus, PDLSCs are capable of differentiating into an osteoblastic lineage, and are considered as a good regenerative medicine candidate for treatment of bone defects.

Bone regeneration and repair is an important therapeutic area in the fields of dental implants and orthopedic treatment. In order to enhance this process, a microenvironment that promotes the osteogenic differentiation of dental-derived stem cells or BMMSCs is needed. Cell adhesion is known to be one of the primary cellular processes associated with tissue regeneration and wound healing [14]. Recently, a mussel-inspired polydopamine (PDA) coating material, formed by the oxidative polymerization of dopamine, was identified, and this material is considered an attractive substrate for biomedical applications [15]. Since PDA exhibits strong adhesion to various substrates, a number of studies have investigated the cellular responses affected by the PDA-modified surfaces. One recent study reported that the PDA coating can be applied to practically any type of substrate without cellular toxicity [16]. Another previous study found that PDA-coated glass substrate enhances the adherence and proliferation of myoblast cells [17]. Additionally, surface modification with PDA promoted the adhesion and neuronal differentiation of pheochromocytoma 12 cells [18]. Although increasing data have described the cellular regulatory properties of PDA, no study has investigated whether this bioadhesive PDA exerts an influence on PDLSC behavior and osteogenic capacity.

A number of studies demonstrated that following the attachment of cells onto biomaterial substrates, communication between cells and the extracellular matrix (ECM) microenvironment likely involves biochemical signals, which play a critical role in cellular activity, including adhesion, proliferation, and differentiation $[19,20]$. It is well known that the integrin family cell surface receptors, which are crucial components of the cellular sensing system, transmit extracellular signals into intracellular signals [21, 22]. Diverse integrin-linked signaling networks have been found to mediate cell adhesion to ECM and influence specific lineage commitments by certain cell types [23-25]. Thus, cell-substrate interactions can contribute to extensive cellular processes rather than simple mechanical binding operation.

The present study assessed the capability of bioadhesive PDA film to enhance stem cell attachment and osteogenic differentiation of PDLSCs. Moreover, the results of these experiments demonstrated that PDA can serve as an important biomedical substance by acting as an intermediate layer for not only attaching cells to any substrate but also functioning as a cellular modulator. 


\section{Materials and Methods}

\section{Materials}

Fetal bovine serum (FBS) was purchased from Gibco-BRL (Gaithersburg, MD, USA). L-3,4dihydroxyphenylalanine (L-DOPA) was obtained from Sigma (St. Louis, MO, USA). Cell Counting Kit-8 (CCK8) was supplied by Dojindo Laboratories (Japan). QuantiChrom ${ }^{\mathrm{TM}}$ Calcium Assay Kit was obtained from BioAssay Systems (Hayward, CA, USA). Osteocalcin (OCN), osterix (OSX), runt-related transcription factor 2 (RUNX2), integrin $\alpha 5$, integrin $\beta 1$, phosphatidylinositol-3-kinase (PI3K) p110 $\gamma$ and $\beta$-actin antibodies were purchased from Santa Cruz Biotechnology (Dallas, TX, USA). F-actin antibody was supplied by Novus Biologicals (Littleton, CO, USA). Normal rabbit IgG antibody was purchased from Calbiochem (San Diego, CA, USA). Goat anti-mouse and goat anti-rabbit antibodies were supplied by Santa Cruz Biotechnology. Unless otherwise specified, chemicals and laboratory supplies were purchased from Sigma and SPL Labware (SPL Lifescience, Korea), respectively.

\section{Preparation of PDA thin film}

PDA solution was prepared by dissolving $0.02,0.2$, or $2 \mathrm{mg}$ of L-DOPA in $1 \mathrm{ml}$ of $10 \mathrm{mM}$ Tris buffer base ( $\mathrm{pH}$ 8.5, Sigma-Aldrich). The cell culture dishes were treated with the PDA solution overnight at room temperature in the dark, followed by washing with sterile PBS three times. This process leads to selfpolymerized PDA thin film that functions as a bioadhesive. Non-coated polystyrene surface was used as a control.

\section{Periodontal ligament stem cell culture}

Periodontal ligaments were obtained from extracted human molars, which were donated by the Department of Oral and Maxillofacial Surgery of Kyung Hee University. All subjects involved in this study were informed about the purpose and procedures of this study, which was approved by the Review Board of Kyung Hee University. Written informed consent was obtained from all donors or from guardians on behalf of minor participants. Periodontal ligaments, which were collected from the middle third of the root, were cultured in $\alpha$ minimal essential medium ( $\alpha$-MEM; Invitrogen, Carlsbad, CA, USA) containing $10 \%$ FBS, penicillin $(100 \mathrm{U} / \mathrm{mL})$, and streptomycin $(100 \mu \mathrm{g} / \mathrm{mL}$; Gibco-BRL) according to a previously described method. After two passages, cells were subjected to magnetic isolation with antibodies to detect STRO-1 (mesenchymal stem cell marker) antigen (Millipore, Billerica, MA, USA) and magnetic beads (MiltenyiBiotec, Germany). The resulting STRO-1+ cell population was cultured in $\alpha$-MEM plus $10 \%$ FBS at $37^{\circ} \mathrm{C}$ in a humidified chamber containing $5 \% \mathrm{CO}_{2} / 95 \%$ air. All experiments were carried out with cells from passage 4-7.

\section{Osteogenic differentiation of PDLSCS}

Differentiation was initiated by a switch to osteogenic medium, which is comprised of $\alpha$-MEM containing 5\% FBS, $50 \mu \mathrm{g} / \mathrm{mL}$ ascorbic acid, $1 \mu \mathrm{M}$ dexamethasone, and $3 \mathrm{mM} \beta$-glycerophosphate. In each experiment, PDLSCs were plated onto PDA-coated cell culture dishes at different PDA concentrations $[0.02$, 0.2 , and $2 \mathrm{mg} / \mathrm{ml}$ ) for a designated number of days. Osteogenic medium was changed every 2 days before the designed experiments.

\section{Cell proliferation analysis}

Cell proliferation was evaluated using the CCK-8 assay. Briefly, cells were seeded on PDA-coated or uncoated wells of 96 -well culture plates at a density of $1 \times 10^{5}$ cells $/ \mathrm{ml}$ and cultured for $24 \mathrm{hr}$. CCK-8 solution was added to each well for $2 \mathrm{hr}$, and the assay was performed according to the manufacturer's instructions. The optical density was measured at a wavelength of $450 \mathrm{~nm}$ using an ELISA reader (DYNEX, VA, USA). The percentage of cell proliferation was determined relative to the control.

\section{Intracellular calcium assay}

Cells were washed three times with PBS and lysed in $50 \mathrm{mM}$ Tris-HCl buffer (pH 7.0) containing 1\% (v/v) Triton X-100 and $1 \mathrm{mM}$ PMSF without EDTA. The protein content was then quantified according to the method by Bradford [26]. The intracellular calcium content was measured using a calcium assay kit according to the manufacturer's instructions (BioAssay Systems, Hayward, CA, USA.), and the absorbance 
Lee/An/Heo: PDA-Induced Osteogenesis of PDLSCs

was read spectrophotometrically at $602 \mathrm{~nm}$. The calcium content level was expressed as $\mathrm{mg} / 100 \mathrm{mg}$ of protein.

\section{Alkaline phosphatase activity}

Cells were washed twice with PBS and lysed in buffer containing $50 \mathrm{mM}$ Tris- $\mathrm{HCl}(\mathrm{pH} 7.0), 1 \%$ (v/v) Triton X-100, and $1 \mathrm{mM}$ PMSF. The total protein was then quantified using the Bradford procedure. The entire cell lysate was assayed by adding $200 \mu \mathrm{l}$ of p-nitrophenylphosphate (pNPP) as a substrate (Sigma) for $20 \mathrm{~min}$ at $37^{\circ} \mathrm{C}$. The reaction was stopped by adding $3 \mathrm{~N} \mathrm{NaOH}$, and the absorbance was read spectrophotometrically at $405 \mathrm{~nm}$. The enzyme activity was expressed as $\mathrm{mM} / 100 \mu \mathrm{g}$ of protein.

\section{Western blot analysis}

Protein extract samples $(30 \mu \mathrm{g}$ ) were separated by 8-10\% SDS-PAGE and blotted onto polyvinylidene difluoride (PVDF) membranes. The blots were washed with TBST (10 mM Tris- $\mathrm{HCl}$ [pH 7.6], $150 \mathrm{mM} \mathrm{NaCl}$, $0.05 \%$ Tween-20), blocked with 5\% skim milk for $1 \mathrm{hr}$, and incubated with the appropriate primary antibody at the dilutions recommended by the supplier. The membrane was then washed, and the primary antibodies were detected with goat anti-rabbit IgG or goat anti-mouse IgG conjugated to horseradish peroxidase. The blots were developed using the enhanced chemiluminescence (ECL) kit (Thermo Scientific, MA, USA) and exposed to X-ray film (AGFA, Belgium).

\section{Immunocytochemistry}

Cells were fixed for $5 \mathrm{~min}$ in $4 \%$ paraformaldehyde and permeabilized with $0.1 \%$ Triton X-100 for 20 $\mathrm{min}$ at room temperature. After washing with PBS, the cells were incubated for $1 \mathrm{hr}$ at room temperature in blocking solution (1\% BSA in PBS). The cells were treated with primary antibodies $(1: 100$, Santa Cruz Biotechnology) for $4 \mathrm{hr}$ at room temperature. Subsequently, cells were incubated with secondary antibodies (1:500, Santa Cruz Biotechnology) for $2 \mathrm{hr}$ at room temperature. Fluorescence images were obtained using a fluorescence microscope (Fluoview 300, Olympus).

\section{Immunoprecipitation}

Integrin $\beta 1$ was subjected to immunoprecipitation. In brief, $10 \mu \mathrm{l}$ of $200 \mu \mathrm{g} / \mathrm{ml}$ integrin $\beta 1$ antibody was incubated with an equal volume of protein lysates overnight at $4^{\circ} \mathrm{C}$ with occasional shaking. Then, 25 $\mu \mathrm{l}$ of Protein A sepharose beads were added, and the samples were incubated for another $4 \mathrm{hr}$ at $4^{\circ} \mathrm{C}$. The sepharose beads were collected by centrifugation, washed three times with TSA buffer $(0.01 \mathrm{M}$ Tris, $0.14 \mathrm{M}$ $\mathrm{NaCl}, \mathrm{pH}$ 8.0) before separation of proteins by SDS-PAGE.

\section{Statistical analysis}

All data are expressed as mean \pm standard deviation (S.D.). One-way ANOVA was used for multiple comparisons (Duncan's multiple range test) using SPSS software ver. 10.0. The $P$-values $<0.05$ were considered significant.

\section{Results}

PDA film enhances osteogenic differentiation of PDLSCS

To examine the cell response to PDA, cell proliferation was first assessed after cells were cultivated on PDA-coated $(0.02-2 \mathrm{mg} / \mathrm{ml}$ ) or uncoated (control) surfaces for $24 \mathrm{hr}$. As shown in Fig. 1A, PDLSCs cultured on the PDA thin film exhibited a higher proliferation rate than those growing on control surface. The PDA-induced proliferation occurred in a dose-dependent manner. Subsequently, the ALP activity and intracellular calcium levels $\left(\left[\mathrm{Ca}^{2+}\right]_{\mathrm{i}}\right)$ of PDLSCs were analyzed as a marker of osteogenic differentiation. The $\left[\mathrm{Ca}^{2+}\right]_{\mathrm{i}}$ was increased more in cells on PDA than in cells on the control surface, and a marked increase was observed in cells grown on $2 \mathrm{mg} / \mathrm{ml}$ PDA (2.2-fold increase vs. control; $P<0.05$; Fig. 1B). Figure 1C shows that the ALP activity in cells cultured on PDA film was significantly increased compared to that in the control group on day 4, which represents an early stage of 
A

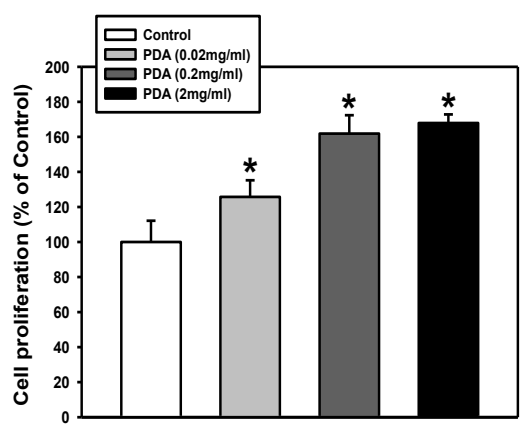

C

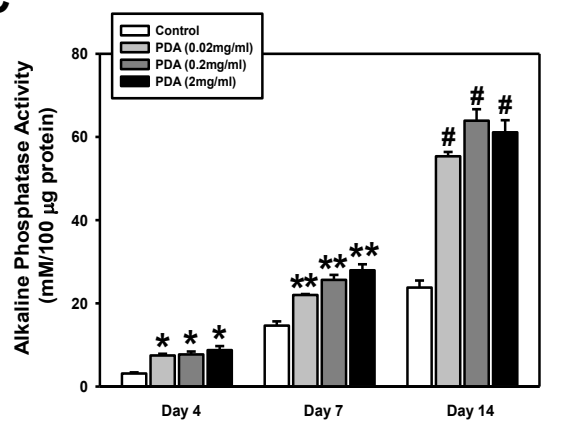

B

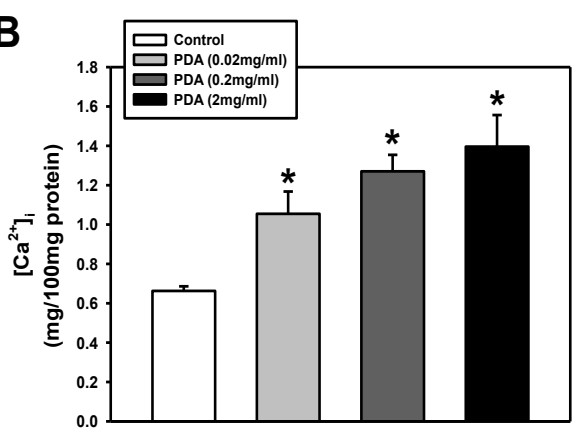

D

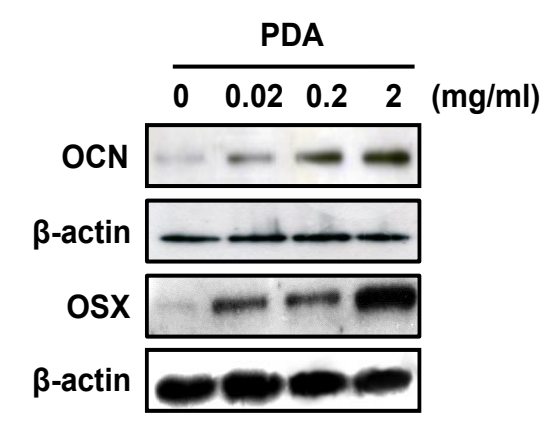

Fig. 1. Cell proliferation and osteogenic differentiation of PDLSCs cultured on PDA-modified surfaces. (A) Cells were cultured on PDA film $(0.02,0.2$, or $2 \mathrm{mg} / \mathrm{ml})$ for $24 \mathrm{hr}$, and then the proliferation rate was assessed as described in the Materials and Methods. (B) Intracellular calcium levels were examined after 7 days of osteogenic induction. (C) ALP activity was determined after 4, 7, and 14 days of osteogenic induction. (D) Cells were cultured on PDA film for 7 days, and then protein levels of OCN and OSX were determined by western blot analysis using total protein lysates. The values reported are the means \pm S.D. of five independent experiments. ${ }^{*} P<0.05$, ${ }^{* *} P<0.05$, and ${ }^{\#} P<0.05$ vs. control value.

osteogenic differentiation, and was even increased further on day 7 and day 14, suggesting that bioadhesive PDA can stimulate the osteogenic potential of PDLSCs.

\section{Effects of PDA on protein levels of osteogenic factors}

In the present study, we also assessed the effects of the PDA film on the osteogenic differentiation of PDLSCs by following the protein expression of the osteogenic markers OCN, OSX, and RUNX2 7 days after osteogenic induction. Western blot analysis showed that the protein levels of OCN and OSX were increased in the presence of PDA in a dose-dependent manner (Fig. 1D). Immunofluorescence images with OCN, OSX, and RUNX2 confirmed that the differentiation of PDLSCs into an osteogenic lineage was more pronounced on the PDA film than on the uncoated surface (Fig. 2A-C).

\section{Integrin $\alpha 5$ and $\beta 1$ are upregulated during osteogenic differentiation of PDLSCs on PDA} film

In order to better understand the interaction between PDLSCs and PDA film, we investigated cell adhesion on PDA by evaluating the expression of integrins $\alpha 5$ and $\beta 1$, which are considered as adhesion receptors. The immunofluorescence intensities of integrin $\alpha 5$ and $\beta 1$ were consistent with results of the western blot analysis (Fig. 3A, B). We also examined the patterns of actin filaments, which link the cytoskeleton to integrin to mediate cell attachment. The immunofluorescence of F-actin in cells on PDA film was much more intense than in control cells (Fig. 3C). As shown in Fig. 4A, the protein levels of integrin $\alpha 5$ and $\beta 1$ in cells grown on PDA film were markedly increased compared to those in cells of the control group. These results show the enhanced adhesive potential of PDLSCs on PDA film 
Fig. 2. Protein levels of (A) OCN, (B) OSX, and (C) RUNX2 were detected by immunostaining (magnification 200x). The nuclei were stained with DAPI (blue staining).

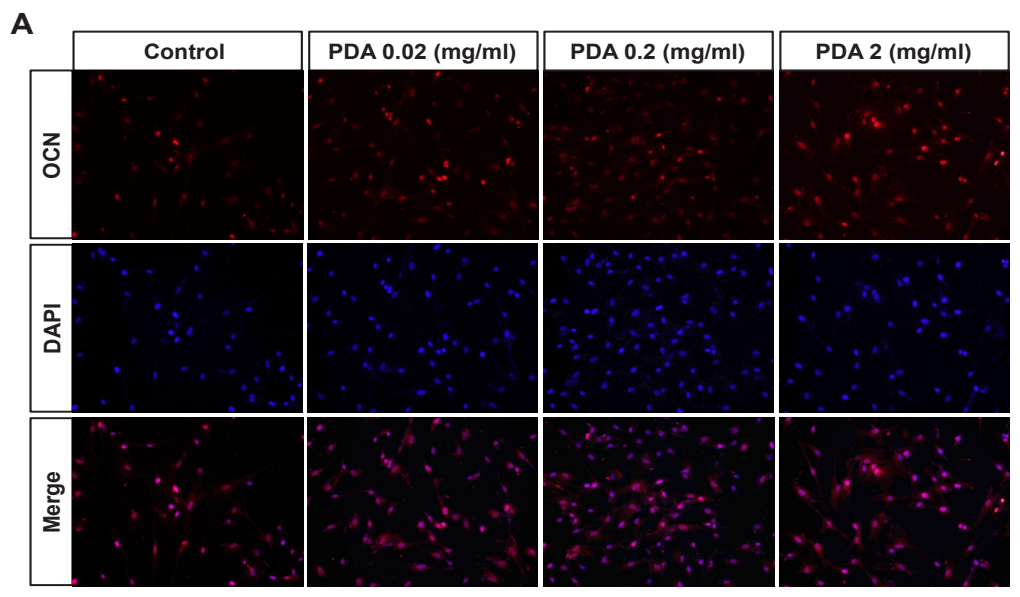

B

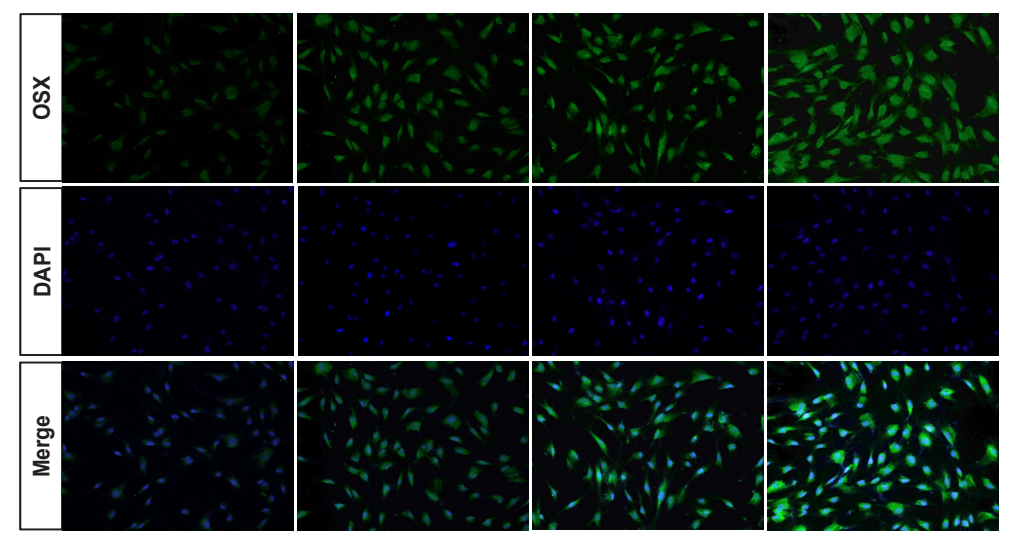

C

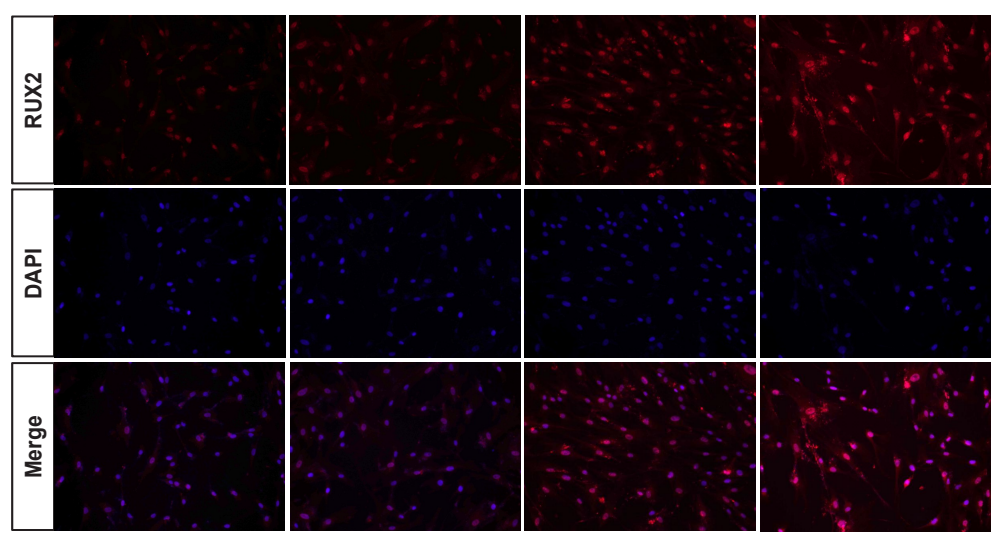

and indicate that the integrin family, particularly integrins $\alpha 5$ and $\beta 1$, can be involved in the attachment of PDLSCs on bioadhesive PDA.

PI3K signaling pathway associated with integrin is involved in PDA-mediated osteogenic differentiation of PDLSCS

In order to identify whether the PI3K pathway is involved in PDLSC osteogenesis in response to PDA, western blot analysis was performed with cell lysates after 7 days in culture.

As shown in Fig. 4B, the protein levels of the PI3K p110 $\alpha$ appeared no changes compared to control group, but PI3K p110 $\gamma$ isoform in PDA cultures were increased in a 
Fig. 3. Protein expression of (A) integrin $\alpha 5$, (B) integrin $\beta 1$, and (C) F-actin were detected by immunostaining (magnification $200 \times$ ). The nuclei were stained with DAPI (blue staining).

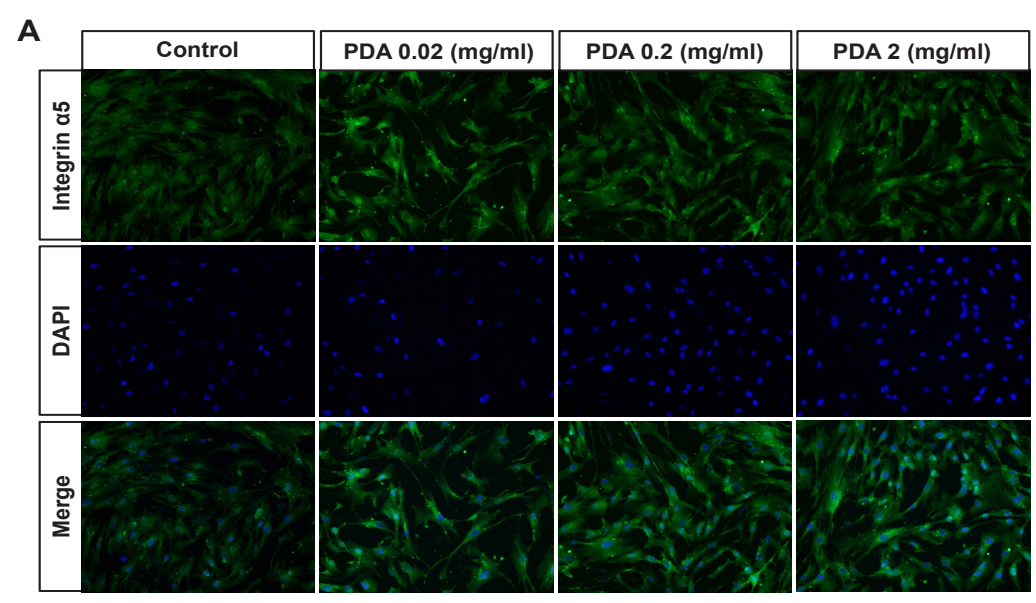

B

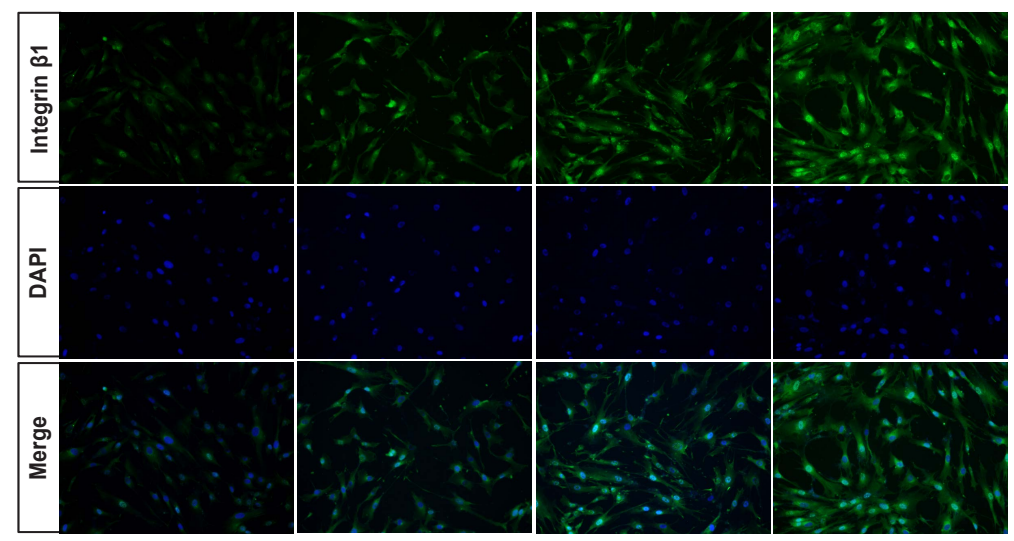

C

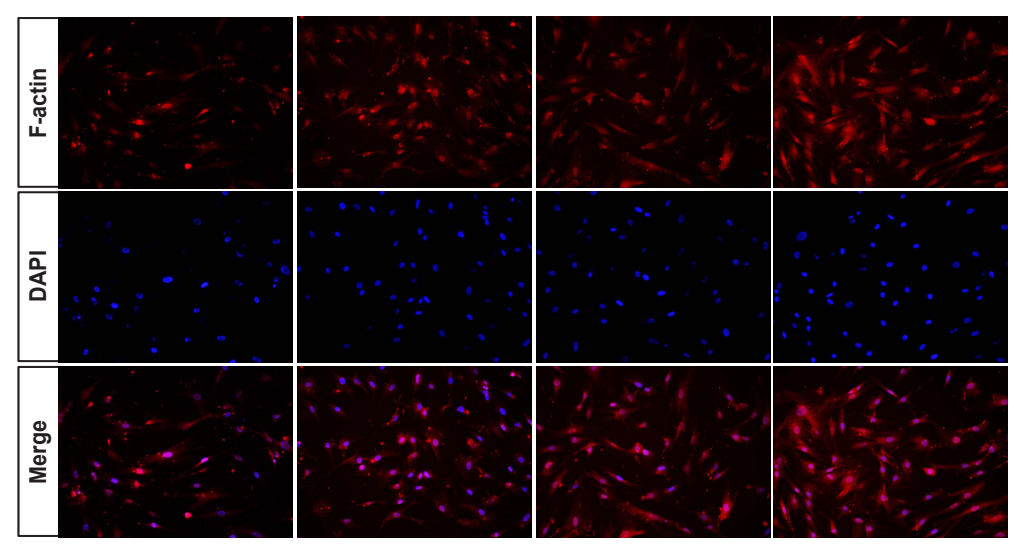

dose-dependent manner. In addition, PDA-mediated increase in PI3K signaling was observed via immunoprecipitation of integrin $\beta 1$, indicating a direct interaction between integrin $\beta 1$ and PI3K signaling (Fig. 4C). In order to confirm whether PI3K signaling is involved in PDAstimulated osteogenesis of PDLSCs, cells were treated with LY294002, a potent inhibitor of PI3K. As shown in Fig. 4D, the levels of the osteogenic maker proteins OCN and OSX were also attenuated in response to LY294002. Moreover, the increased ALP activity in cells grown on PDA-modified surface was significantly reduced by LY294002 treatment (Fig. 4E). Thus, these data suggest that PDA promotes PDLSC osteogenesis by activating the integrinmediated PI3K pathways. 
Fig. 4. Interaction between integrin and PI3K signaling in PDLSCs cultured on PDA-modified surfaces. (A) Expression of integrin $\alpha 5$ and integrin $\beta 1$ proteins in PDLSCs on PDA-modified surfaces. Cells were cultured on PDA film for 7 days, and then the protein levels of integrin $\alpha 5$ and integrin $\beta 1$ were determined by western blot analysis using total protein lysates. (B) Cells were cultured on PDA film, and then protein levels of PI3K p110 $\alpha$ and PI3K p110 $\gamma$ were detected after 7 days of incubation. (C) Total protein was immunoprecipitated with integrin $\beta 1$ antibody or rabbit IgG (as a negative control) and then subjected to western blot analysis for PI3K p110 $\gamma$ or integrin $\beta 1$. Cells were treated with LY294002 $\left(10^{-6} \mathrm{M}\right)$ for $48 \mathrm{hr}$ before (D) western blot analysis and (E) ALP activity. The values reported are the means \pm S.D. of five independent experiments. ${ }^{*} P<0.05$ vs. control value.

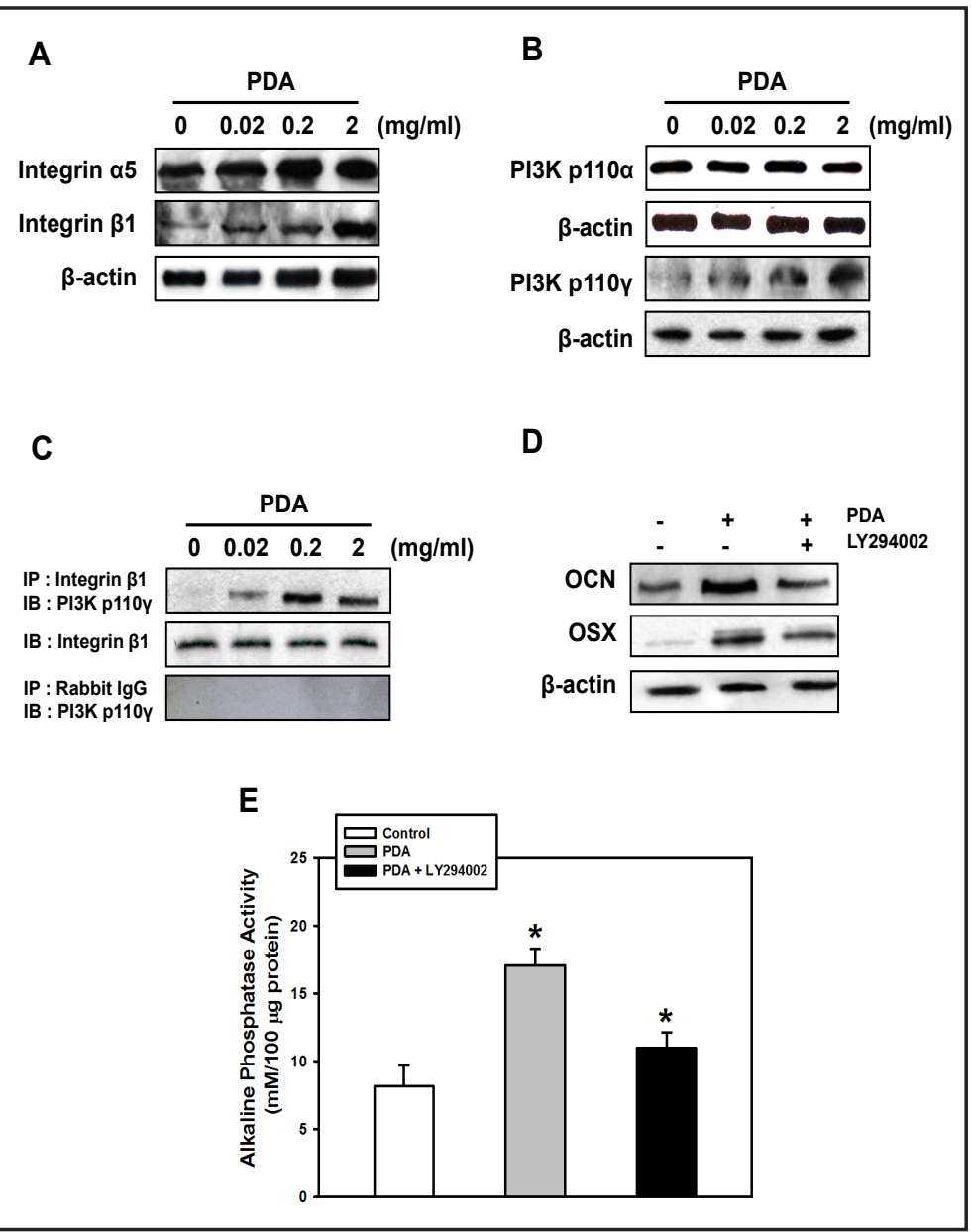

\section{Discussion}

The present study demonstrated enhanced osteogenic potential of PDLSCs in response to PDA film with possible involvement of integrin-PI3K interaction in this process. The PDA coating, which is formed from dopamine polymerization under alkaline $\mathrm{pH}$ conditions, is associated with simultaneous adsorption of various biomolecules and attachment of cells $[18,27]$. This capacity of PDA allows the fine environment concept particularly with respect to how microenvironments can participate in regulation of cellular activity. Importantly, this milieu can modulate the stem cell function under different patho-physiological conditions. Indeed, we have shown PDA-mediated stem cell responses, such as an increase in cell proliferation and osteogenic differentiation of PDLSCs. Recent studies reported that PDAcoated zirconia exhibited better cyto-compatibility, including increased cell spreading and proliferation, than did uncoated specimens [28]. In addition, the osteogenic differentiation of human MSCs was increased more when cells were cultured on PDA-coated poly (L-lactide) (PLLA) fibers than those cultured on non-coated PLLA [29]. Thus, the present results suggest that PDA is an easy biocompatible substrate to improve PDLSC activity.

Cell adhesive mechanisms play important roles in many physiological processes, such as embryonic development, tissue repair, and stem cell regulation. In the present study, we confirmed that the cell adhesion receptors integrin $\alpha 5$ and $\beta 1$ were highly expressed in the PDLSCs cultured on PDA film during osteogenic induction. The integrins $\alpha 5$ and $\beta 1$ comprise the fibronectin receptor that mediates such cellular responses as adhesion, migration, assembly of extracellular matrix, and various signal cascades [30]. Consistent with our results, PDA coating increased endogenous fibronectin and the $\alpha 5 \beta 1$ integrin receptor 
Fig. 5. Hypothesized model of the signaling pathways underlying the PDA effect on osteogenic differentiation of PDLSCs. When PDLSCs are cultured on PDA-modified surfaces, integrin $\alpha 5$ and $\beta 1$ activity is enhanced leading to the PI3K signaling stimulation and eventually induces the osteogenic differentiation of PDLSCs.

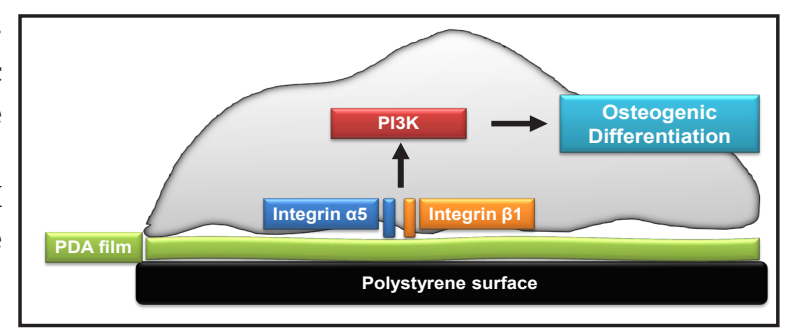

to improve HUVECs adhesion and development [31]. These findings suggest the contact mechanism that connects cells and PDA film.

Integrin receptors have been known to be involved in osteogenic differentiation of certain cell types. One study showed that integrin $\alpha 5$ enhanced osteoblast differentiation of MSCs via activation of various signaling pathways [32]. The same group also reported that integrin $\alpha 5$ increased insulin-like growth factor 2 (IGF2) and IGF binding protein 2 (IGFBP2) expression in BMMSCs and subsequently, stimulated osteogenic differentiation of these cells [23]. Moreover, integrin was regulated by the stiffness of the matrix during osteogenic induction, and knockdown of this integrin by siRNA downregulated the osteogenic phenotype in MSCs [33]. Indeed, integrin plays an important role in cytoskeletal changes during osteogenesis of stem cells $[34,35]$. Thus, these prime sensing integrins that respond to the surroundings can translate signals into osteogenic differentiation events.

Cellular responses depend on the interactions of intrinsic signals with extrinsic factors from the environment. The present findings demonstrated that one intracellular signaling pathway, the PI3K pathway, contributes to the osteogenic differentiation of PDLSCs. PI3Ks are a family of lipid kinases that catalyze the phosphorylation of plasma membrane lipid phosphatidylinositol, and these pathways network with other signaling complexes to lead changes in various cellular events [36]. PI3Ks are arranged into three classes: class I, II, and III. The confirmed PI3K p110 $\gamma$ belongs to class IB catalytic isoform, which is activated by the $\beta / \gamma$ subunits of G protein-coupled receptor (GPCR) [37, 38]. We have also verified whether other isoforms, such as class IA p110 $\alpha$, are regulated during osteogenesis of PDLSCs on PDA film; however, there were no significant alterations in the signaling proteins (data not shown). We can assume that PDA substrate-stimulated PI3K may be involved in GPCR activation despite the need for further detailed study.

Using immunoprecipitation, we showed a direct interaction between integrin $\beta 1$ and PI3K signals in PDLSCs cultured on PDA film. Integrin receptor pathways are well known as one of the stimuli for PI3K signaling activation [39]. Thus, this study demonstrated that integrin-PI3K linkages also mediate cell adhesion and regulate osteogenic differentiation of PDLSCs. Subsequently, our findings confirmed that the inhibition of PI3K blocked the increase of ALP activity and osteogenic marker proteins in PDLSCs on PDA film. Previous studies showed that the osteogenic transcription factors RUNX2 and OSX interact with PI3K signaling networks, implicating PI3K in the regulation of the osteogenic transcription process $[40,41]$. Moreover, PI3K signaling and its downstream effectors were associated with bone formation in a craniofacial disorder model [42]. Thus, we suggest that PI3K signaling across the integrin adhesion receptor can lead to osteogenic induction of PDLSCs in response to PDA (Fig. 5).

In conclusion, the present study demonstrated that when cells were cultured on PDA film, osteogenic differentiation of PDLSCs was enhanced through activation of integrinlinked PI3K signaling pathways. PDA is a promising bioadhesive and bioactive substrate for controlling PDLSC behavior, and this substrate may serve as a therapeutic substance for bone regeneration in the field of dental implants and orthopedic surgery.

\section{Acknowledgement}

This work was supported by a grant from Kyung Hee University in 2013 (KHU20131081). 


\section{Cellular Physiology and Biochemistry}

Lee/An/Heo: PDA-Induced Osteogenesis of PDLSCs

\section{References}

1 Seo BM, Miura M, Gronthos S, Bartold PM, Batouli S, Brahim J, Young M, Robey PG, Wang CY, Shi S: Investigation of multipotent postnatal stem cells from human periodontal ligament. Lancet 2004;364:149155.

- Feng F, Akiyama K, Liu Y, Yamaza T, Wang TM, Chen JH, Wang BB, Huang GT, Wang S, Shi S: Utility of PDL progenitors for in vivo tissue regeneration: a report of 3 cases. Oral Dis 2010;16:20-28.

-3 Nakashima M, Iohara K, Sugiyama M: Human dental pulp stem cells with highly angiogenic and neurogenic potential for possible use in pulp regeneration. Cytokine Growth Factor Rev 2009;20:435-440.

-4 Singhatanadgit W, Donos N, Olsen I: Isolation and characterization of stem cell clones from adult human ligament. Tissue Eng A 2009;15:2625-2636.

-5 Zainal Ariffin SH, Kermani S, Megat Abdul Wahab R, Senafi S, Zainal Ariffin Z, Abdul Razak M: In vitro chondrogenesis transformation study of mouse dental pulp stem cells. ScientificWorldJournal 2012;2012:827149.

6 Gay I, Chen S, MacDougall M: Isolation and characterization of multipotent human periodontal ligament stem cells. Orthod Craniofac Res 2007;10:149-160.

7 Lindroos B, Mäenpää K, Ylikomi T, Oja H, Suuronen R, Miettinen S: Characterisation of human dental stem cells and buccal mucosa fibroblasts. Biochem Biophys Res Commun 2008;368:329-335.

8 Xu J, Wang W, Kapila Y, Lotz J, Kapila S: Multiple differentiation capacity of STRO-1+/CD146+ PDL mesenchymal progenitor cells. Stem Cells Dev 2009;18:487-496.

-9 Gronthos S, Mankani M, Brahim J, Robey PG, Shi S: Postnatal human dental pulp stem cells (DPSCs) in vitro and in vivo. Proc Natl Acad Sci USA 2000;97:13625-13630.

10 Yu BH, Zhou Q, Wang ZL: Periodontal ligament versus bone marrow mesenchymal stem cells in combination with Bio-Oss scaffolds for ectopic and in situ bone formation: A comparative study in the rat. J Biomater Appl 2014;29:243-253.

-11 Zhang Q, Shi S, Liu Y, Uyanne J, Shi Y, Shi S, Le AD: Mesenchymal stem cells derived from human gingiva are capable of immunomodulatory functions and ameliorate inflammation-related tissue destruction in experimental colitis. J Immunol 2009;183:7787-7798.

12 Park SY, Kim KH, Gwak EH, Rhee SH, Lee JC, Shin SY, Koo KT, Lee YM, Seol YJ: Ex vivo bone morphogenetic protein 2 gene delivery using periodontal ligament stem cells for enhanced re-osseointegration in the regenerative treatment of peri-implantitis. J Biomed Mater Res A 2014 doi: 10.1002/jbm.a.35145.

13 Moshaverinia A, Chen C, Xu X, Akiyama K, Ansari S, Zadeh HH, Shi S: Bone regeneration potential of stem cells derived from periodontal ligament or gingival tissue sources encapsulated in RGD-modified alginate scaffold. Tissue Eng Part A 2014;20:611-621.

14 Liu X, Lim JY, Donahue HJ, Dhurjati R, Mastro AM, Vogler EA: Influence of substratum surface chemistry/ energy and topography on the human fetal osteoblastic cell line hFOB 1.19: Phenotypic and genotypic responses observed in vitro. Biomaterials 2007;28:4535-4550.

-15 Lee H, Scherer NF, Messersmith PB: Single-molecule mechanics of mussel adhesion. Proc Natl Acad Sci USA 2006;103:12999-13003.

- 16 Ku SH, Ryu J, Hong SK, Lee H, Park CB: General functionalization route for cell adhesion on non-wetting surfaces. Biomaterials 2010;31:2535-2541.

-17 Lynge ME, Ogaki R, Laursen AO, Lovmand J, Sutherland DS, Städler B: Polydopamine/liposome coatings and their interaction with myoblast cells. ACS Appl Mater Interfaces 2011;3:2142-2147.

- 18 Bhang SH, Kwon SH, Lee S, Kim GC, Han AM, Kwon YH, Kim BS: Enhanced neuronal differentiation of pheochromocytoma 12 cells on polydopamine-modified surface. Biochem Biophys Res Commun 2013;430:1294-1300.

19 Geiger B, Spatz JP, Bershadsky AD: Environmental sensing through focal adhesions. Nat Rev Mol Cell Biol 2009;10:21-33.

20 Vogel V, Sheetz M: Local force and geometry sensing regulate cell functions. Nat Rev Mol Cell Biol 2006; 7:265-275.

21 Anselme K: Osteoblast adhesion on biomaterials. Biomaterials 2000;21:667-681.

22 Xiao G, Wang D, Benson MD, Karsenty G, Franceschi RT: Role of the alpha 2-integrin in osteoblast-specific gene expression and activation of the Osf2 transcription factor. J Biol Chem 1998;273:32988-32994. 


\section{Cellular Physiology $\quad$ Cell Physiol Biochem 2014;34:1824-1834 and Biochemistry \\ Lee/An/Heo: PDA-Induced Osteogenesis of PDLSCs}

23 Hamidouche Z, Fromigué O, Ringe J, Häupl T, Marie PJ: Crosstalks between integrin alpha 5 and IGF2/ IGFBP2 signalling trigger human bone marrow-derived mesenchymal stromal osteogenic differentiation. BMC Cell Biol 2010;11:44.

24 Sipilä K, Haag S, Denessiouk K, Käpylä J, Peters EC, Denesyuk A, Hansen U, Konttinen Y, Johnson MS, Holmdahl R, Heino J: Citrullination of collagen II affects integrin-mediated cell adhesion in a receptorspecific manner. FASEB J 2014; 28:3758-3768.

-25 Tang CH, Yang RS, Huang TH, Lu DY, Chuang WJ, Huang TF, Fu WM: Ultrasound stimulates cyclooxygenase-2 expression and increases bone formation through integrin, focal adhesion kinase, phosphatidylinositol 3-kinase, and Akt pathway in osteoblasts. Mol Pharmacol 2006;69:2047-2057.

-26 Bradford MM: A rapid and sensitive method for the quantitation of microgram quantities of protein utilizing the principle of protein-dye binding. Anal Biochem 1976;72:248-254.

27 Lai M, Cai K, Zhao L, Chen X, Hou Y, Yang Z: Surface functionalization of TiO2 nanotubes with bone morphogenetic protein 2 and its synergistic effect on the differentiation of mesenchymal stem cells. Biomacromolecules 2011;12:1097-1105.

28 Liu YT, Lee TM, Lui TS: Enhanced osteoblastic cell response on zirconia by bio-inspired surface modification. Colloids Surf B Biointerfaces 2013;106:37-45.

29 Rim NG, Kim SJ, Shin YM, Jun I, Lim DW, Park JH, Shin H: Mussel-inspired surface modification of poly (L-lactide) electrospun fibers for modulation of osteogenic differentiation of human mesenchymal stem cells. Colloids Surf B Biointerfaces 2012;91:189-197.

- 30 Goessler UR, Bugert P, Bieback K, Stern-Straeter J, Bran G, Sadick H, Hörmann K, Riedel F: In vitro analysis of integrin expression in stem cells from bone marrow and cord blood during chondrogenic differentiation. J Cell Mol Med 2009;13:1175-1184.

31 Wang JL, Ren KF, Chang H, Jia F, Li BC, Ji Y, Ji J: Direct adhesion of endothelial cells to bioinspired poly(dopamine) coating through endogenous fibronectin and integrin $\alpha 5 \beta 1$. Macromol Biosci 2013;13:483-493.

-32 Hamidouche Z, Fromigué O, Ringe J, Häupl T, Vaudin P, Pagès JC, Srouji S, Livne E, Marie PJ: Priming integrin alpha5 promotes human mesenchymal stromal cell osteoblast differentiation and osteogenesis. Proc Natl Acad Sci USA 2009;106:18587-18591.

33 Shih YR, Tseng KF, Lai HY, Lin CH, Lee OK: Matrix stiffness regulation of integrin-mediated mechanotransduction during osteogenic differentiation of human mesenchymal stem cells. J Bone Miner Res 2010;26:730-738.

-34 Salasznyk RM, Klees RF, Williams WA, Boskey A, Plopper GE: Focal adhesion kinase signaling pathways regulate the osteogenic differentiation of human mesenchymal stem cells. Exp Cell Res 2007;313:22-37.

-35 Treiser MD, Yang EH, Gordonov S, Cohen DM, Androulakis IP, Kohn J, Chen CS, Moghe PV: Cytoskeletonbased forecasting of stem cell lineage fates. Proc Natl Acad Sci USA 2010;107:610-615.

-36 Cantley LC: The phosphoinositide 3-kinase pathway. Science 2002;296:1655-1657.

-37 Hohenester S, Gates A, Wimmer R, Beuers U, Anwer MS, Rust C, Webster CR: Phosphatidylinositol-3-kinase p110 $\gamma$ contributes to bile salt-induced apoptosis in primary rat hepatocytes and human hepatoma cells. J Hepatol 2010;53:918-926.

-38 Stoyanov B, Volinia S, Hanck T, Rubio I, Loubtchenkov M, Malek D, Stoyanova S, Vanhaesebroeck B, Dhand R, Nürnberg B, Gierschik P, Seedorf K, Hsuan JJ, Waterfiled MD, Wetzker R: Cloning and characterization of a G protein-activated human phosphoinositide-3 kinase. Science 1995;269:690-693.

-39 Dillon RL, White DE, Muller WJ: The phosphatidyl inositol 3-kinase signaling network: implications for human breast cancer. Oncogene 2007;26:1338-1345.

-40 Fujita T, Azuma Y, Fukuyama R, Hattori Y, Yoshida C, Koida M, Ogita K, Komoro T: Runx2 induces osteoblast and chondrocyte differentiation and enhances their migration by coupling with PI3K-Akt signaling. J Cell Biol 2004;166;85-95.

-41 Rached MT, Kode A, Xu L, Yoshikawa Y, Paik JH, Depinho RA, Kousteni S: FoxO1 Is a Positive Regulator of Bone Formation by Favoring Protein Synthesis and Resistance to Oxidative Stress in Osteoblasts. Cell Metabol 2010;11:147-160.

-42 Rokutanda S, Fujita T, Kanatani N, Yoshida CA, Komori H, Liu W, Mizuno A, Komori T: Akt regulates skeletal development through GSK3, mTOR, and FoxOs. Dev Biol 2009;328:78-93. 